\title{
Study for ReVersibility of Experimental Cholesteatoma Using Mongolian Gerbil
}

\author{
Keehyun Park, MD, Young-Myoung Chun, MD, Sung-Kyun Moon, MD, \\ Yun-Hoon Choung, DDS, MD, Jin-Suk Lee, MD and Youngju Kim, MD \\ Department of Otolaryngology, Ajou UniVersity School of Medicine, Suwon, Korea
}

Korean Journal of Otolaryngology-Head and Neck Surgery 2003;46(5):372-80.

The following original article from Korean Journal of Otolaryngology-Head and Neck Surgery, "Study for ReVersibility of Experimental Cholesteatoma Using Mongolian Gerbils" by Keehyun Park, published on May 2003 has been withdrawn from publication by agreement among the authors, the journal Editor, Sung Won Chae, and the publisher ML communications Co., Ltd. The retraction has been agreed due to substantial overlap of the content of this article with previously published one. The author and the Journal apologize to readers.

Sung Won Chae, MD, PhD

Editor

Korean Journal of Otorhinolaryngology-Head and Neck Surgery 